\title{
ARBORIZAÇÃO URBANA E QUALIFICAÇÃO DA PAISAGEM
}

\author{
URBAN AFFORESTATION AND QUALIFICATION LANDSCAPE
}

\author{
Jussara Maria Basso* \\ Rodrigo Studart Corrêa**
}

\begin{abstract}
RESUMO
Este trabalho quantificou o papel de diferentes espécies arbóreas na amenização do microclima na área central de Campo Grande (MS) por meio da avaliação da contribuição da arborização urbana sobre o conforto térmico do espaço público da cidade. A cidade de Campo Grande apresenta clima tropical com estação seca, característico do Cerrado brasileiro. Apontar espécies arbóreas capazes de qualificar a paisagem e amenizar o microclima urbano torna-se importante. Neste trabalho buscou-se avaliar a melhoria da sensação de conforto térmico alcançada com a amenização da radiação solar caracterizada pelas diferenças apresentadas nas temperaturas superficiais de ruas e calçadas sob influência de árvores adultas das espécies mais utilizadas na arborização da área central da cidade. Para tanto foram feitas medições com um termômetro sob a sombra e o entorno próximo de doze espécies existentes nas calçadas. Os resultados indicaram a dimensão, em relação ao conforto térmico, que uma espécie apresenta perante outras e possibilitaram uma projeção da amenização do calor no recinto urbano, o que pode contribuir na tomada de decisões de planejamento e desenho paisagístico da cidade.
\end{abstract}

Palavras-chave: Arborização urbana. Qualidade ambiental. Qualificação da paisagem urbana.

\section{ABSTRACT}

This study quantified the role of different species of trees in mitigation the microclimate in the central area of Campo Grande - MS by evaluating the contribution of urban trees on the thermal comfort of the public space of the city. The city of Campo Grande presents a tropical climate with a dry season, characteristic of the Brazilian Cerrado, and point tree species able to qualify the landscape and soften the urban microclimate becomes important. This work aimed to evaluate the improvement of thermal comfort achieved with the mitigation of solar radiation characterized by differences presented in the surface temperatures of streets

* $\quad$ Arquiteta e Urbanista pela Universidade Federal do Rio Grande do Sul (UFRGS). Especialista em Reabilitação Ambiental Sustentável Arquitetônica e Urbanística pela Universidade de Brasília (UnB). Mestre em Planejamento Urbano e Regional pelo Programa de Pós-Graduação em Planejamento Urbano e Regional da UFRGS. Professora do curso de Arquitetura e Urbanismo da Universidade para o Desenvolvimento da Região do Pantanal (UNIDERP) de 2003 a 2012. Rua da Paz, 779, Centro, 79020-250, Campo Grande, MS, Brasil.

jussara.basso@yahoo.com.br

** Engenheiro Ambiental pelo Instituto de Engenheiros da Austrália e Engenheiro Agrônomo pela Universidade de Brasília (UnB). Especialista em Degradação de Solos e Desertificação pela Universidade Tecnológica de Dresden (Alemanha). M.Sc. em Ecologia pela UnB. Ph.D. em Solos e Nutrição de Plantas pela Universidade de Melbourne (Austrália). Trabalha há duas décadas com revegetação como forma de Recuperação, Requalificação e Restauração de Ambientes e Ecossistemas. Caixa Postal 04.401, 70910-900, Asa Norte, Brasília, DF, Brasil. rodmanga@yahoo.com.br 
and sidewalks under the influence of mature trees of the species used in forestry over the downtown area. For so, measurements were made with a thermometer in the shade and near surroundings of twelve species existing on sidewalks. The results indicated the size, in relation to thermal comfort, a species is presenting to others and allowed a projection of the alleviation of heat in the urban enclosure, which can help in decision making for planning and landscape design in the city.

Keywords: Urban forestry. Environmental quality. Qualifying urban landscape.

\section{INTRODUÇÃO}

A arborização urbana, um importante componente da paisagem e do conforto ambiental, cumpre diversas funções no sistema de espaços livres de uma cidade: meIhorias no microclima, diminuição de polvição do ar, sonora e visual, abrigo para a fauna que vive nas cidades, qualificação de lugares urbanos e sua identidade com as comunidades. Essas melhorias favorecem a apropriação dos espaços e a conexão com a natureza dentro do ambiente urbano.

A escolha adequada das espécies arbóreas a serem utilizadas é resultado de um jogo complexo, sendo necessários estudos que subsidiem as decisões de planejamento, projeto, plantio e manutenção da rede de vegetação de porte arbóreo em cidades, principalmente em biomas onde esses estudos sejam raros. O planejamento dessa rede de espécies arbóreas deve ser organizado de forma a incluir a malha urbana completa, permitir o desenvolvimento saudável e coerente das espécies ao longo do tempo e explorar os aspectos estéticos inerentes a cada espécie.

O município de Campo Grande, capital do Estado do Mato Grosso do Sul, aprovou em setembro de 2011 a lei do Plano Diretor de Arborização Urbana (PDAU), que dá diretrizes sobre planejamento, implantação e conservação da arborização urbana com o intuito de preservação, manejo e expansão das áreas arborizadas da cidade. Sob essas diretrizes, durante os anos de 2011 e 2012, o poder público iniciou a execução do Projeto Via Verdel, que trata da arborização de passeios públicos em áreas residenciais e visa trabalhar em conjunto com a população local de bairros e regiões menos arborizadas por meio do plantio de espécies arbóreas apropriadas. Parte desse projeto abrange ruas do centro da cidade, região já arborizada com espécies de grande porte, que apresentam atualmente 40 a 50 anos de existência, e que vêm sofrendo um processo de erradicação e substituição por novas espécies.

O objetivo deste trabalho foi avaliar o desempenho das espécies selecionadas para plantio - pelo Projeto Via Verde - nas calçadas das ruas residenciais do centro da cidade em relação à temperatura resultante nas proximidades dessas espécies quando adultas. Também foram estudadas possibilidades de uso dessa informação como estratégia de projeto na qualificação da paisagem da cidade, de forma a favorecer a utilização mais assídua dos espaços públicos pelos pedestres.

Via Verde é uma das ações do Programa de Arborização Urbana de acordo com a Secretaria de Meio Ambiente. Disponível em: <http://www.capital.ms.gov.br/semadur/canaisTexto?id_can=3957> .

Acesso em: 16 out. 2011. 


\section{PREMISSAS: ESPAÇOS LIVRES E QUALIDADE AMBIENTAL}

A rede de espaços livres e sua composição são importantes para as funções neles desenvolvidas e para as condições ambientais relacionadas à ventilação, insolação, permeabilidade do solo e cobertura vegetal (CAMPOS et al., 2009).

De acordo com Cormier e Pellegrino (2008), espaços livres urbanos podem apresentar-se paisagisticamente belos, serem tratados para desempenhar funções infraestruturais relacionadas a conforto ambiental, manejo de águas urbanas, biodiversidade, alternativas de circulação, acessibilidade e imagem local.

Buscando soluções de planejamento e projeto ambientalmente e socialmente eficientes, o enfoque bioclimático procura a adequada utilização dos recursos naturais, relacionando-os ao uso dos espaços e às atividades neles desenvolvidas. (BUSTOS ROMERO, 2001).

\subsection{CLIMA URBANO E MICROCLIMA}

O clima é um importante fator responsável pela variação das paisagens e pela diversidade biológica na Terra. Nas cidades, influi no desenvolvimento de tipologias e variações arquitetônicas, assim como em diferentes hábitos e costumes. Sofre influência de diversos fatores locais, como topografia, presença de vegetação, tipo de solo, capacidade térmica dos materiais presentes na superfície, proximidade de corpos d'água, balanço entre espaços construídos e espaços abertos. (BARBIRATO; TORRES; SOUZA, 2011).

O clima de um entorno próximo ou o microclima urbano, de acordo com Bustos Romero (2001), é conformado primeiramente por elementos térmicos e do ar: radiação solar, temperatura e velocidade do ar, umidade relativa e precipitação. Absorção, reflexão, evaporação e condensação acontecem em resposta a esses elementos térmicos e do ar. Por meio do balanço dos mesmos, o microclima atua no conforto e na energia requerida para aquecimento ou resfriamento de edificações, influindo também na utilização e permanência nos espaços abertos públicos.

microclima urbano influencia e é influenciado pelas ações humanas sobre o meio. Portanto, a possibilidade de controlá-lo é interesse de arquitetos e planejadores envolvidos em desenhar espaços exteriores que foquem a otimização ambiental e a valorização humana e busquem assegurar maior conforto ambiental e emocional a seus usuários.

\subsection{CONFORTO AMBIENTAL NO ESPAÇO LIVRE URBANO}

No espaço livre urbano, o conforto humano pode ser afetado por diversos parâmetros. $O$ conforto térmico urbano e a qualidade ambiental dependem dos recursos naturais - incluindo clima e morfologia do lugar - e da capacidade do homem para criar condições artificiais que melhorem o que a natureza oferece (BARBIRATO; TORRES; SOUZA, 2011). 
Diz-se que uma pessoa está num ambiente físico confortável quando se sente em condição de neutralidade em relação ao mesmo: pode observá-lo e senti-lo sem preocupação ou incômodo (CORBELLA; YANNAS, 2003 apud AMORIM; BRAGA, 2009). O conforto desse ambiente representa a situação mais desejável quando se quer favorecer a permanência nos lugares. $O$ conforto ambiental, além do conforto psicológico, abrange aspectos como os confortos térmico, lumínico, acústico e ergonômico.

Segundo a norma americana ANSI/ASHRAE, conforto térmico pode ser considerado como a "condição na qual um indivíduo exprime satisfação em relação ao ambiente que o circunda", sendo que pelo menos $80 \%$ dos indivíduos pesquisados expressem satisfação com o mesmo. De acordo com Amorim e Braga (2009), os parâmetros utilizados para medir a satisfação dos indivíduos com o ambiente térmico são os mesmos que conformam o clima: radiação solar, temperatura e velocidade do ar e umidade relativa. Parâmetros pessoais, como vestimenta e atividade desenvolvida num determinado momento pelo indivíduo também compõem os atributos do conforto ambiental. Pode-se levar em conta que a percepção de conforto também depende do "conforto adaptativo" 2 , em que a temperatura na qual as pessoas se sentem em conforto possui relação com as temperaturas habituais da região.

Particularmente em relação ao conforto térmico em ambientes abertos, Mascaró e Mascaró (2002) ressaltam que a quantidade de radiação solar que penetra um recinto urbano, a área sombreada, o fator de céu visível, a cor e textura das fachadas dos edifícios que o delimitam, sua orientação em relação ao sol e ao vento e a relação entre cheios e vazios que o configuram definem o comportamento térmico e a situação de conforto.

A radiação solar, após o vento, é o segundo parâmetro mais influente no conforto externo. Para haver situação de conforto nos espaços livres devem existir, simultaneamente, condições de ventos fracos e baixa temperatura radiante (AIT-AMEUR, 1999). Para Bueno, Labaki e Vianna (2001), a atenuação da radiação solar é um parâmetro essencial, que deve ser levado em conta ao se buscar o conforto térmico urbano.

A radiação solar é a energia eletromagnética emitida pelo sol e parcialmente absorvida pela atmosfera terrestre. A parcela de radiação que penetra é absorvida pelas superfícies terrestres e reemitida ao meio, produzindo aumento da temperatura do ar. Essa reemissão varia segundo o albedo de cada superfície, isto é, segundo a porção de radiação refletida pela superfície (BARBIRATO; TORRES; SOUZA, 2011). Portanto, a escolha de pavimentos de baixo nível de albedo e o controle da penetração da radiação solar nos recintos urbanos pela utilização de vegetação adequada são estratégias passivas de condicionamento no projeto, que podem trazer, sem grandes custos, maior conforto ambiental humano em climas quentes.

Temperatura de conforto térmico relacionando a adaptação individual à temperatura externa média mensal registrada em ${ }^{\circ} \mathrm{C}$ (PEREIRA; ASSIS, 2010). 


\subsection{A VEGETAÇÃO}

A vegetação possibilita a criação de microclimas urbanos diferenciados por meio do sombreamento, da redução da velocidade dos ventos, da proteção solar do conjunto urbano edificado e pela redução das temperaturas urbanas, pela evapotranspiração e retenção de umidade do solo e do ar. De acordo com Mascaró e Mascaró (2002), o sombreamento é uma das principais funções da arborização urbana nas cidades com clima quente. Nesse aspecto, uma das recomendações de Bustos Romero (2011) para desenho bioclimático do espaço público é evitar ruas e estacionamentos sem arborização.

Uma árvore pode controlar a radiação solar direta que chega à superfície do solo, diminuindo o calor irradiado a partir dele e, consequentemente, diminuindo a temperatura do ar próximo a ela. Como as folhas possuem baixo índice de reflexão, absorvem a radiação solar incidente e bloqueiam significativa quantidade da radiação solar direta. Dessa forma, as árvores, dependendo da densidade da sua folhagem e extensão e espessura de sua copa, podem interceptar grandes quantidades de radiação solar (BARBIRATO, TORRES; SOUZA, 2011).

Vários estudos atestam que, sob agrupamentos arbóreos, a temperatura do ar é menor que nas áreas expostas à radiação solar. $\bigcirc$ efeito se estende e há redução da temperatura de superfícies verticais (fachadas) ou horizontais (calçamentos). Por exemplo, para Mascaró e Mascaró (2002), espécies de Jacarandá (Dalbergia sp.) e Cinamomo (Melia azedarach) reduzem de $2,3^{\circ} \mathrm{C}$ a $5,5^{\circ} \mathrm{C}$ a temperatura superficial das fachadas durante o verão na cidade de Porto Alegre. Estudo de Bueno, Labaki e Santos (1999) demonstrou que a sombra da Sibipiruna (Poincianella pluviosa) tem capacidade de atenuação de radiação solar 15\% maior que a sombra do Ipê-roxo (Handroanthus impetiginosus) na cidade de Campinas.

Com enfoque semelhante, procura-se, neste trabalho, avaliar quais as diferenças de radiação solar sob a sombra de diferentes espécies arbóreas, relacionando estas com o conforto térmico que se pode conseguir no espaço público da cidade de Campo Grande,

\section{MATERIAIS E MÉTODOS}

A radiação solar é um dos aspectos que mais influencia na sensação de conforto térmico e, de acordo com Amorim e Braga (2009), pode ser caracterizada pelas temperaturas superficiais dos elementos componentes do ambiente. Essa abordagem e esse parâmetro foram escolhidos para o presente trabalho.

No trabalho de campo, foram coletados dados da temperatura nas superfícies horizontais das calçadas e das ruas em torno de vários indivíduos arbóreos das espécies selecionadas: três por espécie, sempre que existentes na área; uma medição por mês, nos meses de julho e agosto de 2012, em típicos dias quentes e secos, na hora mais quente do dia - entre $12 \mathrm{~h}$ e $14 \mathrm{~h}$ - com temperaturas do ar entre $30^{\circ}$ e $32^{\circ} \mathrm{C}$.

Foram tomadas quatro medidas da temperatura da superfície da calçada (calçadas de cimento) em direção à área sombreada pela copa: ao lado do tronco, a 1 metro do 
tronco, a 3 metros do tronco, a 1 metro fora da sombra da copa (a pleno sol) ${ }^{3}$. Foram tomadas duas medidas em torno da árvore, no leito da rua asfaltada - uma à sombra desta, quando a copa sombreava parte do asfalto (o que não acontecia em todos os casos), e uma ao sol. Por conta da falta de sombra no asfalto em alguns casos, nas tabelas esses dados não aparecem. As medições foram feitas com termômetro infravermelho com mira a laser, marca Cason, modelo $\mathrm{CA} 380\left(-32^{\circ} \mathrm{C}\right.$ a $\left.380^{\circ} \mathrm{C}\right)$, precisão $\pm 2^{\circ} \mathrm{C}$.

Os dados foram tabulados em planilha Excel e foi realizada análise de estatística descritiva - médias aritméticas, desvios padrão e coeficientes de variação (CV) - para avaliar a homogeneidade das medições. Os resultados foram organizados em tabelas e foram feitos gráficos dos resultados mais significativos.

Com os resultados das temperaturas superficiais sob as espécies, pode-se avaliar a influência das copas na redução das temperaturas, apontar quais as espécies mais eficientes na amenização do microclima e, com isso, trabalhar alternativas de projeto que favoreçam a amenização térmica.

\section{1 ÁREA DE ESTUDO}

Campo Grande, cidade com população próxima a 800 mil habitantes, situada no cerrado brasileiro e com altitude de 532 metros, tem clima tropical quente-seco, com chuva no verão e seca no inverno.

O período seco vai de julho a outubro. As maiores temperaturas acontecem em outubro e se mantêm altas até março, quando as médias máximas ficam acima de $30^{\circ} \mathrm{C}$ (figura 1).

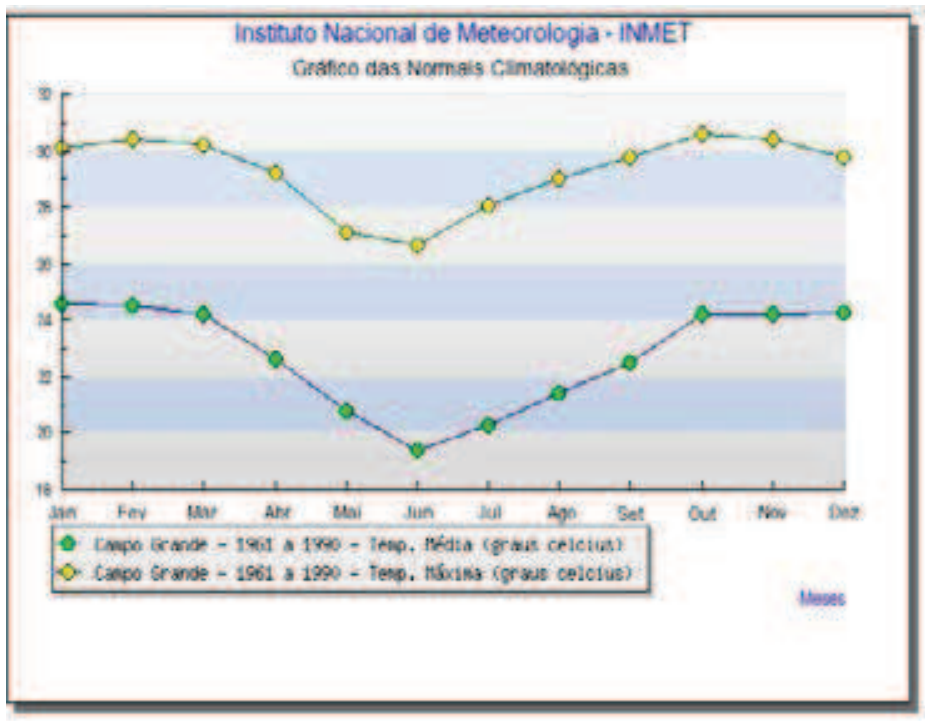

Figura 1 Gráfico de temperaturas médias e máximas.

Fonte: Instituto Nacional de Meteorologia (INMET) - 2012.

Estas medições estão nas tabelas 6, 7 e 8, pelas letras (b) a 1 metro do tronco; (c) a 3 metros do tronco; (d) a 1 metro fora da sombra da copa - a pleno sol. 
A cidade, espraiada com grandes vazios vegetados e vários pequenos córregos dentro de seu perímetro (EBNER, 1999), possui índice de cobertura vegetal $74 \mathrm{~m}^{2} / \mathrm{habitante}$.

A arborização urbana das ruas varia de 51 a 97 árvores por quilômetro de passeio público, sendo que, no centro da cidade, encontramos uma média de 70 árvores por quilômetro de passeio. Aspectos do porte imponente da arborização da área central de Campo Grande podem ser percebidos nas imagens das figuras 2, 3 e 4.
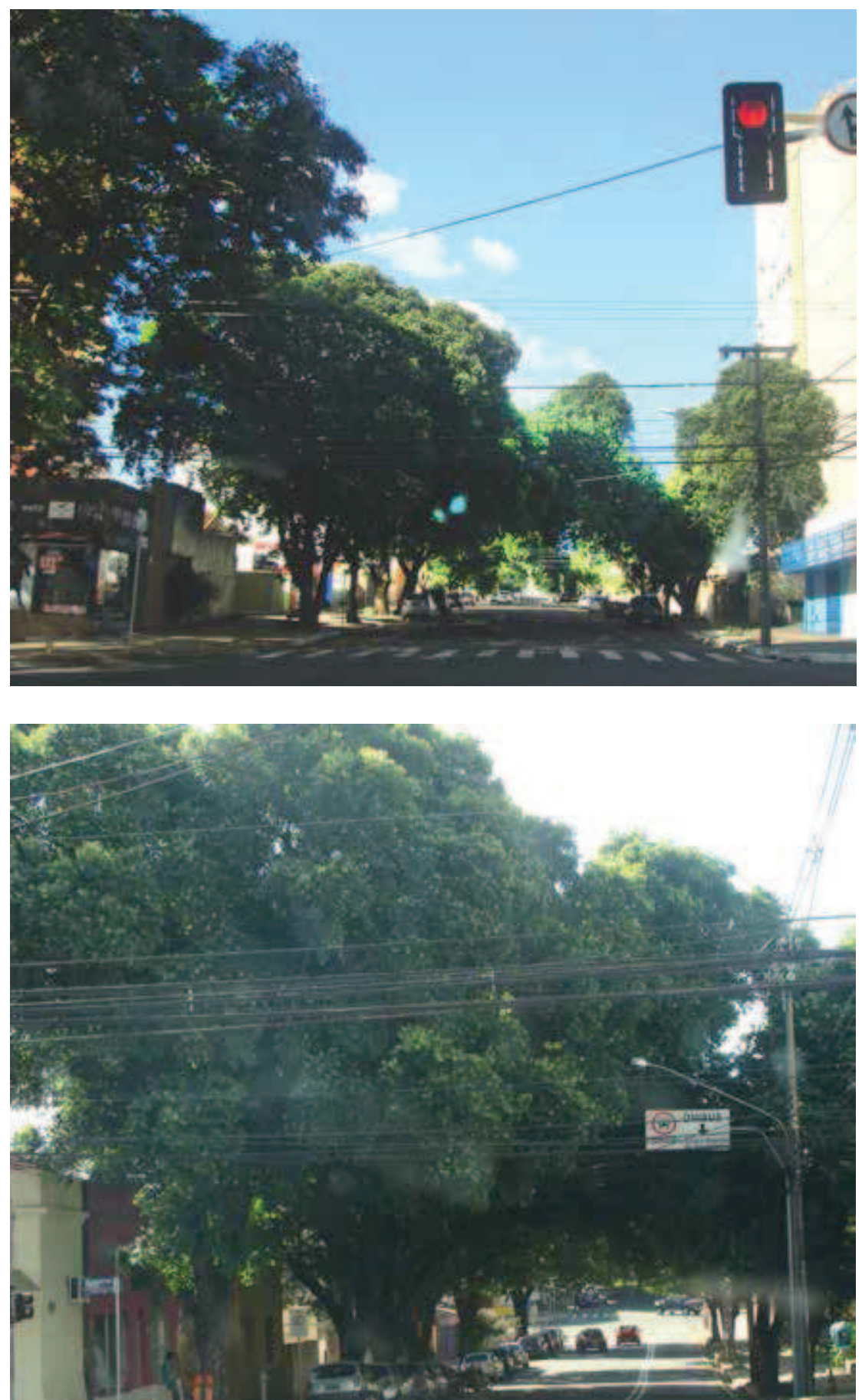

Figura 2

Aspectos da

arborização da área central de Campo Grande. Fonte: Acervo de Jussara Basso 18 ago. 2011.

Figura 3

Aspectos da arborização da área central de Campo Grande. Fonte: Acervo de Jussara Basso 18 ago. 2011. 


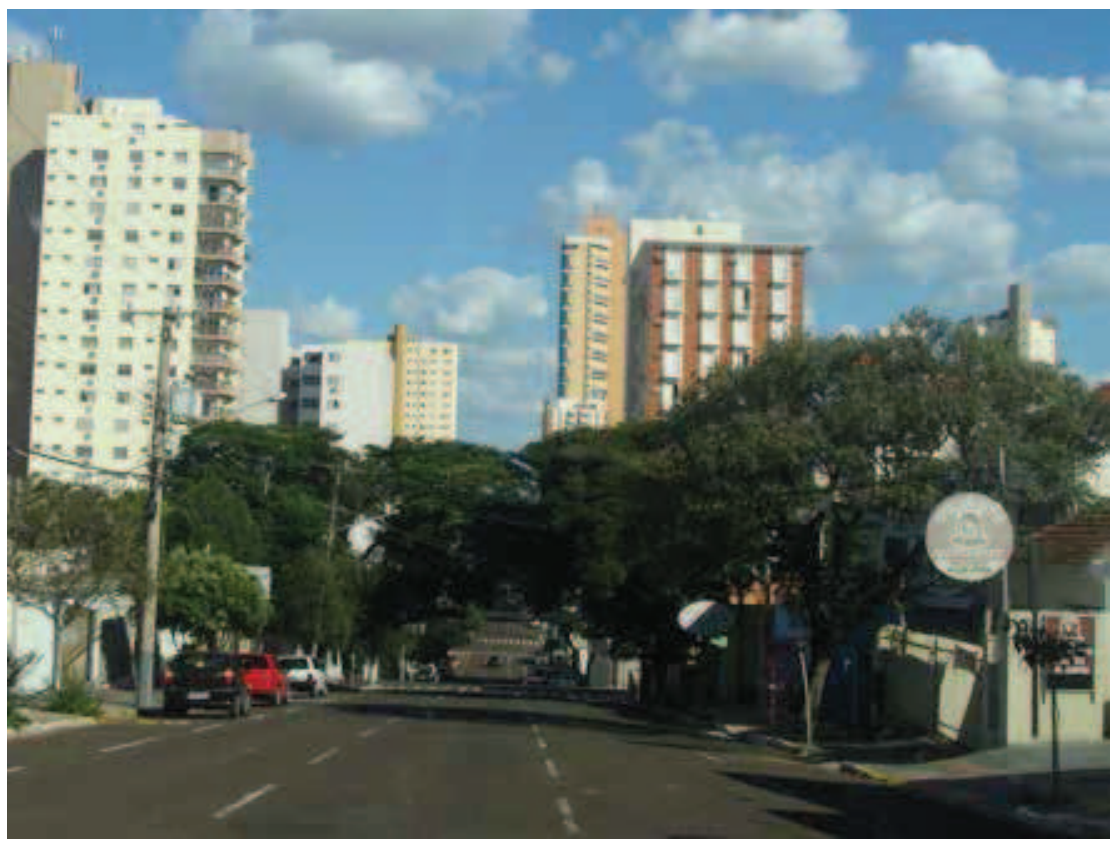

Figura 4

Aspectos da arborização da área central de Campo Grande. Fonte: Acervo de Jussara Basso 18 ago. 2011

A área selecionada para as medições foi o setor Centro e entorno próximo por ser a de mais antiga arborização da cidade - da década de 1970. A paisagem é marcada pelo porte avantajado das árvores e pela beleza do seu conjunto. Porém, esse conjunto encontra-se ameaçado por podas deformantes, infestações que levam a enfraquecimento e preconceitos que favorecem a retirada das árvores ${ }^{4}$.

\subsection{ESCOLHA DAS ESPÉCIES PARA AVALIAÇÃO}

De acordo com os levantamentos feitos pelo Plano Diretor de Arborização Urbana (PDAU/2010), as espécies predominantes na arborização urbana do bairro Centro de Campo Grande hoje são a Sibipiruna (Caesalpinia peltophoroides), com 32,25\% das ocorrências; o Oiti (Licania tormentosa) com 10,56\%; a Magnólia-amarela (Michelia champaca), com 9,07\%; o Resedá (Lagerstroemia indica), com 8,99\%; o Ficus (Ficus benjamina), com $8,79 \%$.

Outras espécies, encontradas em menor proporção, são: Murta (Murraya paniculata), Palmeira imperial (Roystonea oleracea), Ligustro (Ligustrom lucidum), Quaresmeira (Tibouchina granulosa), Pata-de-vaca (Bauhinia variegata), Monguba (Pachira aquatica) e Ipê-roxo (Tabebuia spp). O PDAU/2010 recomenda para plantio nas calçadas do Centro, principalmente, oito espécies.

\footnotetext{
A troca anual dos folículos - característica da Sibipiruna (Caesalpinia peltophoroides), espécie predominante na área central -, incomoda a população, que os vê como sujeira, precisando varrer as calçadas. Tal incômodo sempre é mencionado no desejo de troca da espécie. Há, também, resistência ao domínio do espaço visual pela folhagem densa, o que leva à retirada das antigas árvores de grande porte das calçadas, principalmente em paralelo ao avanço do uso comercial na região.
} 
Tabela 1 Recomendações para Arborização de Campo Grande pelo PDAU - 2010

\begin{tabular}{l|c|c}
\hline \multicolumn{1}{c|}{ Nome popular } & Nome científico & Altura/Porte \\
\hline Angico-vermelho & $\begin{array}{c}\text { Anadenanthera falcata e } \\
\text { A. peregrina }\end{array}$ & Grande porte \\
\hline Farinha-seca & Albiza hasslerii & Grande porte \\
\hline Ipê & Tabebuia spp. & De pequeno a grande porte \\
\hline Magnólia-amarela & Michelia champaca & Médio porte \\
\hline Murta-de-cheiro & Murraya paniculata & Pequeno porte \\
\hline Pata-de-vaca & Bauhinia variegata & Médio porte \\
\hline Resedá & Lagerstroemia indica & Pequeno porte \\
\hline $\begin{array}{l}\text { Sibipiruna } \\
\text { (principalmente para reposição) }\end{array}$ & Caesalpinia peltophoroides & Grande porte \\
\hline $\begin{array}{l}\text { Quaresmeira (só onde não } \\
\text { precisar de poda) }\end{array}$ & Tibouchina granulosa & Pequeno porte \\
\hline $\begin{array}{l}\text { Cássia-rosa (só em situações } \\
\text { especiais) }\end{array}$ & Cassia grandis & Grande porte \\
\hline
\end{tabular}

Fonte: Plano Diretor de Arborização Urbana (PDAU) - 2010.

Adaptação: Jussara Basso - 2012.

Além de recomendar espécies regionais para experimentação, pois não são tradicionalmente plantadas na cidade (tabela 2).

Tabela 2 Recomendações para Experimentação na Arborização de Campo Grande pelo PDAU - 2010

\begin{tabular}{l|c|c}
\hline \multicolumn{1}{c|}{ Nome popular } & Nome científico & Altura/Porte \\
\hline Angelim & Andira SP. e Andira anthelmia & Grande porte \\
\hline Barbatimão & Stryphiodendron adstringens & Pequeno porte \\
\hline Capitão-do-mato & Terminalia argentea & Médio a grande porte \\
\hline Cedro & Cedrela fissilis & Grande porte \\
\hline Copaíba & Copaifera langsdorffii & Grande porte \\
\hline Cumbaru & Dipteryx & Médio a grande porte \\
\hline Cupiúba, pau-pombo & Tapirira guianensis & Médio porte \\
\hline Dedaleira & Lafoensia pacari & Pequeno a médio porte \\
\hline Falso barbatimão, cinzeiro & Dimorphandra mollis & Médio porte \\
\hline Ipê verde & Cybistax antisyphilitica & Médio porte \\
\hline Mandiocão & Scheffkera morototoni & Grande porte \\
\hline Manduvi & Sterculia striata & Médio porte \\
\hline Angelim-do-cerrado & Andira cuiabensis & Pequeno porte \\
\hline Olho-de-cabra & Ormosia arbórea & Grande porte \\
\hline
\end{tabular}




\begin{tabular}{l|c|c}
\hline \multicolumn{1}{c|}{ Nome popular } & Nome científico & Altura/Porte \\
\hline Pau-de-tucano & Vochysia bifalcata & Pequeno a grande porte \\
\hline Pau-ferro & Caesalpinia férrea & Grande porte \\
\hline Pau-pombo & Rapanea umbelata & Pequeno porte \\
\hline Pau-terrinha & Qualea parviflora & Pequeno porte \\
\hline Pau-terra grande & Qualea grandiflora & Médio porte \\
\hline
\end{tabular}

Fonte: PDAU - 2010

Adaptação: Jussara Basso - 2012.

O programa Via Verde, atualmente em execução, plantou na área central, até meados de abril de 2012, as seguintes espécies em duas etapas, $1^{a}$ e $3^{a}$ (tabela 3 ).

Tabela 3 VIA VERDE - Características e \% das Espécies mais Plantadas pelo Programa até Abril 2012

\begin{tabular}{|c|c|c|c|c|c|c|}
\hline \multicolumn{2}{|c|}{$\begin{array}{l}\text { Proporções } \\
\text { (\%) }\end{array}$} & \multirow[t]{2}{*}{$\begin{array}{l}\text { Nome popular } \\
\text { Nome científico }\end{array}$} & \multirow[t]{2}{*}{ Altura/Porte } & \multirow[t]{2}{*}{ Copa } & \multirow[t]{2}{*}{ Folhagem } & \multirow[t]{2}{*}{ Origem } \\
\hline Etpl & Etp3 & & & & & \\
\hline 25,8 & 22,1 & $\begin{array}{l}\text { Magnólia- } \\
\text {-amarela } \\
\text { Michelia } \\
\text { champaca }\end{array}$ & $\begin{array}{l}10 \mathrm{~m} \\
\text { Médio } \\
\text { porte }\end{array}$ & $6 \mathrm{~m}$ & $\begin{array}{c}\text { Folhas médias. Sombra } \\
\text { densa. Perenifólia. }\end{array}$ & Ásia. \\
\hline 16,5 & 26,3 & $\begin{array}{l}\text { Quaresmeira } \\
\text { Tibouchina } \\
\text { granulosa }\end{array}$ & $\begin{array}{l}6-8 \mathrm{~m} \\
\text { Pequeno } \\
\text { porte }\end{array}$ & $\begin{array}{l}\text { 6-8 m } \\
\text { Arredon- } \\
\text { dada }\end{array}$ & $\begin{array}{c}\text { Folhas rijas de } \\
\text { 15-20 cm. Sombra. } \\
\text { Densa. } \\
\text { Perenifólia / } \\
\text { Semidecídua }\end{array}$ & $\begin{array}{l}\text { Mata } \\
\text { atlântica. }\end{array}$ \\
\hline 27,0 & 0,86 & $\begin{array}{c}\text { Murta-de-cheiro } \\
\text { Murraya } \\
\text { paniculata }\end{array}$ & $\begin{array}{c}6 \mathrm{~m} \\
\text { Pequeno } \\
\text { porte }\end{array}$ & $\begin{array}{l}4 \mathrm{~m} \\
\text { Frondosa }\end{array}$ & $\begin{array}{c}\text { Folhas pequenas. Sombra } \\
\text { densa. Perenifólia. }\end{array}$ & $\begin{array}{l}\text { India; } \\
\text { Malásia. }\end{array}$ \\
\hline 0,5 & 20,7 & $\begin{array}{c}\text { Pata-de-vaca } \\
\text { Bauhinia } \\
\text { variegata }\end{array}$ & $\begin{array}{l}\text { 6-10 m } \\
\text { Médio } \\
\text { porte }\end{array}$ & $\begin{array}{l}\text { 6-8 m } \\
\text { Irregular }\end{array}$ & $\begin{array}{c}\text { Folhas glabas de } \\
\text { 6-12 cm. Sombra densa. }\end{array}$ & Índia \\
\hline 12,2 & 2,3 & $\begin{array}{l}\text { Dedaleira } \\
\text { Lafoensia } \\
\text { pacari }\end{array}$ & $\begin{array}{c}5-10 \mathrm{~m} \\
10-15 \mathrm{~m} \\
\text { Pequeno a } \\
\text { Médio porte }\end{array}$ & $10 \mathrm{~m}$ & $\begin{array}{c}\text { Folhas coriáceas } 8-15 \\
\text { cm Copa densa. Sombra } \\
\text { leve. Decídua. }\end{array}$ & $\begin{array}{l}\text { Floresta de } \\
\text { altitude e } \\
\text { Cerrado. }\end{array}$ \\
\hline 4,6 & 6,9 & Ipê branco & $\begin{array}{l}\text { 7-16 m } \\
\text { Médio porte }\end{array}$ & $\begin{array}{l}\text { 7-10 m } \\
\text { Aberta e } \\
\text { alongada }\end{array}$ & $\begin{array}{c}\text { Folhas compostas de 6-11 } \\
\mathrm{cm} \text {. Folhagem densa. } \\
\text { Sombra densa quando } \\
\text { com folhas. Decídua. }\end{array}$ & $\begin{array}{l}\text { Floresta } \\
\text { semide- } \\
\text { cídua. } \\
\text { Pantanal. }\end{array}$ \\
\hline
\end{tabular}




\begin{tabular}{|c|c|c|c|c|c|c|}
\hline \multicolumn{2}{|c|}{$\begin{array}{l}\text { Proporções } \\
\text { (\%) }\end{array}$} & $\begin{array}{l}\text { Nome popular } \\
\text { Nome científico }\end{array}$ & Altura/Porte & Copa & Folhagem & Origem \\
\hline 8,0 & - & $\begin{array}{l}\text { Bálsamo } \\
\text { Copaifera } \\
\text { langsdorffii }\end{array}$ & $\begin{array}{l}10-15 \mathrm{~m} \\
\text { Grande } \\
\text { porte }\end{array}$ & $\begin{array}{l}10-13 \text { m } \\
\text { Globosa }\end{array}$ & $\begin{array}{c}\text { Folíolos de } 4-5 \mathrm{~cm} \text {. } \\
\text { Sombra bastante densa. } \\
\text { Semidecídua. }\end{array}$ & $\begin{array}{c}\text { Cerrado } \\
\text { para a } \\
\text { floresta } \\
\text { latifoliada. }\end{array}$ \\
\hline- & 6,5 & $\begin{array}{l}\text { Aroeira-pimenta } \\
\text { Schinus } \\
\text { terebinthifolia }\end{array}$ & $\begin{array}{l}5-9 \mathrm{~m} \\
\text { Pequeno } \\
\text { porte }\end{array}$ & $6-8 \mathrm{~m}$ & $\begin{array}{c}\text { Folíolos de 10-15 cm. } \\
\text { Sombra densa. } \\
\text { Perenifólia. }\end{array}$ & $\begin{array}{c}\text { De } \\
\text { Pernam- } \\
\text { buco } \\
\text { ao RS } \\
\text { várzeas }\end{array}$ \\
\hline 3,0 & 3,1 & $\begin{array}{c}\text { Oiti } \\
\text { Licania } \\
\text { tormentosa }\end{array}$ & $\begin{array}{l}8-15 \mathrm{~m} \\
\text { Grande } \\
\text { porte }\end{array}$ & $\begin{array}{l}15 \mathrm{~m} \\
\text { Frondosa }\end{array}$ & $\begin{array}{c}\text { Folhas médias. Sombra } \\
\text { densa. Perenifólia. }\end{array}$ & $\begin{array}{c}\text { Mata } \\
\text { pluvial } \\
\text { atlântica. }\end{array}$ \\
\hline- & 4,1 & $\begin{array}{c}\text { Aldrago } \\
\text { Pterocarpus } \\
\text { violaceus }\end{array}$ & $\begin{array}{l}8-14 \mathrm{~m} \\
\text { Grande } \\
\text { porte }\end{array}$ & $\begin{array}{c}6 \mathrm{~m} \\
\text { Alongada }\end{array}$ & $\begin{array}{c}\text { Folíolos de } 4-8 \mathrm{~cm} \\
\text { Perenifólia }\end{array}$ & $\begin{array}{l}\text { Floresta } \\
\text { pluvial } \\
\text { atlântica. }\end{array}$ \\
\hline 0,8 & 1,45 & $\begin{array}{l}\text { Resedá } \\
\text { Lagerstroemia } \\
\text { indica }\end{array}$ & $\begin{array}{c}5 \mathrm{~m} \\
\text { Pequeno } \\
\text { porte }\end{array}$ & $3 \mathrm{~m}$ & $\begin{array}{c}\text { Folhas pequenas. } \\
\text { Massa foliar. Reduzida. } \\
\text { Sombra pouco densa. } \\
\text { Decídua. }\end{array}$ & China. \\
\hline- & 2,7 & $\begin{array}{l}\text { Pau-brasil } \\
\text { Caesalpinea } \\
\text { echinata }\end{array}$ & $\begin{array}{l}8-12 \mathrm{~m} \\
\text { Grande } \\
\text { porte }\end{array}$ & $6-10 \mathrm{~m}$ & $\begin{array}{c}\text { Folíolos pequeninos. } \\
\text { Sombra densa. } \\
\text { Semidecídua. }\end{array}$ & $\begin{array}{l}\text { Floresta } \\
\text { pluvial } \\
\text { atlântica. }\end{array}$ \\
\hline- & 1,37 & $\begin{array}{l}\text { Ipê cascudo } \\
\text { Tabebuia } \\
\text { ochracea }\end{array}$ & $\begin{array}{l}\text { 6-14 m } \\
\text { Médio } \\
\text { porte }\end{array}$ & $8-10 \mathrm{~m}$ & $\begin{array}{c}\text { Folíolos pilosos de } \\
\text { 4-9 cm. Sombra leve. } \\
\text { Decídua. }\end{array}$ & $\begin{array}{l}\text { Floresta } \\
\text { semide- } \\
\text { cídua. } \\
\text { Cerrado. }\end{array}$ \\
\hline- & 0,68 & $\begin{array}{l}\text { Sibipiruna } \\
\text { Caesalpinia } \\
\text { peltophoroides }\end{array}$ & $\begin{array}{l}8-16 \mathrm{~m} \\
\text { Grande } \\
\text { porte }\end{array}$ & $\begin{array}{l}15 \mathrm{~m} \\
\text { Frondosa } \\
\text { Alta } \\
\text { aberta }\end{array}$ & $\begin{array}{l}\text { Folhas médias com } \\
\text { múltiplos folíolos. } \\
\text { Sombra densa. } \\
\text { Semidecídua. }\end{array}$ & $\begin{array}{l}\text { Mata } \\
\text { pluvial } \\
\text { atlântica. }\end{array}$ \\
\hline 0,6 & - & $\begin{array}{l}\text { Ipê mirim } \\
\text { Tecoma stans }\end{array}$ & $\begin{array}{l}\text { 4-6 m } \\
\text { Pequeno } \\
\text { porte }\end{array}$ & $\begin{array}{l}4 \mathrm{~m} \\
\text { Irregular }\end{array}$ & $\begin{array}{c}\text { Folhas de } 5 \mathrm{~cm} \text {. } \\
\text { Sombra pouco densa. } \\
\text { Perenifólia. }\end{array}$ & $\begin{array}{l}\text { México. } \\
\text { Invasora } \\
\text { de } \\
\text { pastagens. }\end{array}$ \\
\hline 0,2 & 0,17 & $\begin{array}{l}\text { Ipê-roxo } \\
\text { Tabebuia } \\
\text { heptaphylla }\end{array}$ & $\begin{array}{l}10-15 \mathrm{~m} \\
\text { Grande } \\
\text { porte }\end{array}$ & $\begin{array}{l}10 \mathrm{~m} \\
\text { Aberta e } \\
\text { elevada }\end{array}$ & $\begin{array}{l}\text { Folhas compostas } \\
5-14 \mathrm{~cm} \text {. Sombra } \\
\text { densa quando com } \\
\text { folhas. Decídua. }\end{array}$ & $\begin{array}{c}\text { Mata } \\
\text { pluvial } \\
\text { atlântica. }\end{array}$ \\
\hline- & 0,25 & $\begin{array}{l}\text { Escova-de- } \\
\text {-garrafa } \\
\text { Callistemon sp }\end{array}$ & $\begin{array}{l}\text { 3-7 m } \\
\text { Pequeno } \\
\text { porte }\end{array}$ & $\begin{array}{c}\text { 3-5 m Ramos } \\
\text { pendentes. }\end{array}$ & $\begin{array}{l}\text { Folhas pequenas e } \\
\text { lineares. Perenifólia. }\end{array}$ & Austrália. \\
\hline
\end{tabular}

Fonte: Jussara Basso - 2012. 
Assim, de acordo com os executores do programa, na etapa inicial de implementação do PDAU, temos as maiores proporções de plantio de certas espécies, derivadas, principalmente, das mudas atualmente disponíveis nos viveiros, do desejo expresso dos proprietários dos lotes lindeiros aos plantios ou de sua não concordância com a recomendação do Via Verde e das demandas da companhia de energia, com o resultado expresso na tabela 2.

As espécies arbóreas selecionadas para a medição foram resultados da constatação das espécies existentes de forma mais constante nas calçadas das ruas centrais e das espécies mais significativamente plantadas na área central, pelo Via Verde, desde que existentes como indivíduos adultos. A inexistência de indivíduos adultos de algumas dessas espécies (dedaleira, bálsamo e pau-brasil) nas calçadas do bairro ou proximidades, impossibilitou a sua avaliação. As diferentes variedades de Tabebuia spp foram condensadas na avaliação do ipê-roxo em grande e médio porte, semelhante aos demais ipês e mais abundantes, atualmente, naquelas calçadas.

Tabela 4 Espécies Arbóreas Selecionadas para Avaliação

\begin{tabular}{c|c|c}
\hline Grande Porte & Médio Porte & Pequeno Porte \\
\hline $\begin{array}{c}\text { Sibipiruna } \\
\text { Caesalpinia peltophoroides }\end{array}$ & $\begin{array}{c}\text { Pata-de-vaca } \\
\text { Bauhinia variegata }\end{array}$ & $\begin{array}{c}\text { Resedá } \\
\text { Lagerstroemia indica }\end{array}$ \\
\hline $\begin{array}{c}\text { Oiti } \\
\text { Licania tormentosa }\end{array}$ & $\begin{array}{c}\text { Magnólia-amarela } \\
\text { Michelia champaca }\end{array}$ & $\begin{array}{c}\text { Quaresmeira } \\
\text { Tibouchina granulosa }\end{array}$ \\
\hline $\begin{array}{c}\text { Ipê-roxo } \\
\text { Tabebuia heptaphylla }\end{array}$ & $\begin{array}{c}\text { Ipê-roxo médio } \\
\text { Tabebuia heptaphylla }\end{array}$ & $\begin{array}{c}\text { Murta } \\
\text { Murraya paniculata }\end{array}$ \\
\hline $\begin{array}{c}\text { Aldrago } \\
\text { Pterocarpus violaceus }\end{array}$ & $\begin{array}{c}\text { Escova-de-garrafa } \\
\text { Callistemon SP }\end{array}$ \\
\hline & & $\begin{array}{c}\text { Aroeira pimenta } \\
\text { Schinus terebinthifolia }\end{array}$ \\
\hline
\end{tabular}

Fonte: Jussara Basso - 2012.

Na escolha dos indivíduos arbóreos para efetuar as medições, foram observados aspectos como a idade biológica, características físicas representativas em relação à espécie e disposição em relação ao entorno, a fim de favorecer a adequação dessas medições.

\section{RESULTADOS E DISCUSSÕES}

Os resultados das medições nos meses de julho e agosto de 2012, organizados por extrato de porte das espécies, estão sintetizados nas tabelas 5, 6 e 7. 
Tabela 5 Temperaturas Médias Superficiais à Sombra e ao Sol Próximo às Espécies de Pequeno Porte

\begin{tabular}{|c|c|c|c|c|c|c|c|c|c|c|c|}
\hline \multicolumn{2}{|c|}{$\begin{array}{l}\text { PEQUENO PORTE } \\
\text { Temperaturas }\end{array}$} & \multicolumn{4}{|c|}{ ASFALTO } & \multicolumn{6}{|c|}{ CALÇADA } \\
\hline Julho & Agosto & somb & somb & sol & sol & $\begin{array}{l}\text { somb } \\
\text { (b) * }\end{array}$ & $\begin{array}{l}\text { somb } \\
\text { (b) * }\end{array}$ & $\begin{array}{l}\text { somb } \\
\text { (c) * }\end{array}$ & $\begin{array}{l}\text { somb } \\
\text { (c) * }\end{array}$ & $\begin{array}{l}\text { sol } \\
\text { (d) * }\end{array}$ & $\begin{array}{l}\text { sol } \\
\text { (d) * }\end{array}$ \\
\hline \multirow{3}{*}{ Resedá } & Média & 32,8 & 37,4 & 42,1 & 49,6 & 33,2 & 35,7 & 30 & 31,8 & 34,2 & 41 \\
\hline & DesvP & 3,39 & 3,35 & 1,64 & 1,27 & 7,15 & 5,89 & 2,59 & 3,13 & 3,23 & 4,41 \\
\hline & $C V$ & $10 \%$ & $9 \%$ & $4 \%$ & $6 \%$ & $22 \%$ & $16 \%$ & $9 \%$ & $10 \%$ & $9 \%$ & $11 \%$ \\
\hline \multirow{3}{*}{ Quaresmeira } & Média & 35,2 & 33,9 & 46 & 51,2 & 29,4 & 36,4 & 29,4 & 31,1 & 34 & 45,5 \\
\hline & DesvP & 13,7 & 5,33 & 9,85 & 4,42 & 3,18 & 1,33 & 6,01 & 6,12 & 4,8 & 2,11 \\
\hline & $C V$ & $39 \%$ & $16 \%$ & $21 \%$ & $9 \%$ & $11 \%$ & $4 \%$ & $20 \%$ & $20 \%$ & $14 \%$ & $55 \%$ \\
\hline \multirow{3}{*}{ Murta } & Média & 29,7 & 34,6 & 40,1 & 48,1 & 29,4 & 31,4 & 27,2 & 30,3 & 37,6 & 47,1 \\
\hline & DesvP & 3,95 & 0,63 & 4,41 & 3,6 & 3,31 & 3,91 & 1,53 & 4,42 & 5,75 & 1,72 \\
\hline & $C V$ & $13 \%$ & $2 \%$ & $11 \%$ & $7 \%$ & $11 \%$ & $12 \%$ & $6 \%$ & $15 \%$ & $15 \%$ & $4 \%$ \\
\hline \multirow{3}{*}{$\begin{array}{l}\text { Escova-de- } \\
\text {-garrafa }\end{array}$} & Média & 28,8 & 37,3 & 33,8 & 47,5 & 27,2 & 36,3 & 27,5 & 28,5 & 30,7 & 42,9 \\
\hline & DesvP & 0,7 & - & 1,15 & 2,1 & 2,74 & 4,82 & 1,81 & 0,78 & 0,65 & 1,02 \\
\hline & $C V$ & $2 \%$ & - & $3 \%$ & $4 \%$ & $10 \%$ & $13 \%$ & $7 \%$ & $3 \%$ & $2 \%$ & $2 \%$ \\
\hline \multirow{3}{*}{$\begin{array}{l}\text { Aroeira- } \\
\text {-pimenta }\end{array}$} & Média & 35 & 33,3 & 44,3 & 46,3 & 30,6 & 29,6 & 28,2 & 27,9 & 35,8 & 37,9 \\
\hline & DesvP & 2,54 & 4,39 & 4,85 & 5,24 & 0,85 & 1,3 & 1,15 & 0,75 & 0,66 & 2,4 \\
\hline & CV & $7 \%$ & $13 \%$ & $11 \%$ & $11 \%$ & $3 \%$ & $4 \%$ & $4 \%$ & $3 \%$ & $2 \%$ & $6 \%$ \\
\hline \multirow{3}{*}{ Ipê Mirim } & Média & 29,9 & 33 & 39,5 & 46,5 & 29,9 & 33 & 29,9 & 32,3 & 35,6 & 44,1 \\
\hline & DesvP & 5,36 & 3,63 & 5,13 & 2,99 & 2,26 & 2,33 & 4,95 & 3,67 & 2,16 & 2,75 \\
\hline & $C V$ & $18 \%$ & $11 \%$ & $13 \%$ & $6 \%$ & $8 \%$ & $7 \%$ & $17 \%$ & $11 \%$ & $6 \%$ & $1 \%$ \\
\hline
\end{tabular}

*As letras se referem à localização da medição: (b) a 1 metro do tronco; (c) a 3 metros do tronco; (d) a 1 metro fora da sombra da copa/a pleno sol.

Fonte: Jussara Basso - 2012. 
Tabela 6 Temperaturas Médias Superficiais à Sombra e ao Sol Próxima às Espécies de Médio Porte

\begin{tabular}{|c|c|c|c|c|c|c|c|c|c|c|c|}
\hline \multicolumn{2}{|c|}{$\begin{array}{l}\text { MÉDIO PORTE } \\
\text { Temperaturas }\end{array}$} & \multicolumn{4}{|c|}{ ASFALTO } & \multicolumn{6}{|c|}{ CALÇADA } \\
\hline Julho & Agosto & sombra & sombra & sol & sol & $\begin{array}{c}\text { sombra } \\
(b)^{*}\end{array}$ & $\begin{array}{c}\text { sombra } \\
(b)^{*}\end{array}$ & $\begin{array}{c}\text { sombra } \\
\text { (c) * }\end{array}$ & $\begin{array}{c}\text { sombra } \\
\text { (c) }{ }^{*}\end{array}$ & $\begin{array}{l}\text { sol } \\
\text { (d) * }\end{array}$ & $\begin{array}{l}\text { sol } \\
\text { (d) * }\end{array}$ \\
\hline \multirow{3}{*}{$\begin{array}{l}\text { Pata-de- } \\
\text {-vaca }\end{array}$} & Média & 29,6 & 33,4 & 40 & 45,9 & 27,8 & 30,3 & 30,9 & 31 & 39 & 45,1 \\
\hline & DesvP & 2,55 & 5,23 & 4,41 & 4,72 & 2,94 & 3,18 & 5,62 & 5,32 & 6,65 & 7,06 \\
\hline & $C V$ & $8 \%$ & $16 \%$ & $11 \%$ & $10 \%$ & $11 \%$ & $10 \%$ & $18 \%$ & $17 \%$ & $17 \%$ & $16 \%$ \\
\hline \multirow{3}{*}{ Magnólia } & Média & 25 & 35 & 40,9 & 53,2 & 26,6 & 30,3 & 30,2 & 33,3 & 38,2 & 48,5 \\
\hline & DesvP & 0,75 & - & 4,12 & 3,72 & 0,89 & 1,04 & 5,04 & 2,45 & 2,11 & 4,97 \\
\hline & $C V$ & $3 \%$ & - & $10 \%$ & $7 \%$ & $3 \%$ & $3 \%$ & $17 \%$ & $7 \%$ & $6 \%$ & $10 \%$ \\
\hline \multirow{3}{*}{ Ipê-roxo } & Média & 31,8 & 41,4 & 38,7 & 49,9 & 32,6 & 38,4 & 29,4 & 33,8 & 31,9 & 43,2 \\
\hline & DesvP & 2,33 & 0,07 & 7,9 & 0,55 & 6,36 & 5,33 & 5,12 & 0,15 & 5,76 & 5,38 \\
\hline & $C V$ & $7 \%$ & $0 \%$ & $20 \%$ & $1 \%$ & $20 \%$ & $14 \%$ & $17 \%$ & $1 \%$ & $18 \%$ & $12 \%$ \\
\hline
\end{tabular}

*As letras se referem à localização da medição: (b) a 1 metro do tronco; (c) a 3 metros do tronco; (d) a 1 metro fora da sombra da copa/a pleno sol.

Fonte: Jussara Basso - 2012.

Tabela 7 Temperaturas Médias Superficiais à Sombra e ao Sol Próximas às Espécies de Grande Porte

\begin{tabular}{|c|c|c|c|c|c|c|c|c|c|c|c|}
\hline \multicolumn{2}{|c|}{$\begin{array}{c}\text { GRANDE } \\
\text { PORTE } \\
\text { Temperaturas }\end{array}$} & \multicolumn{4}{|c|}{ ASFALTO } & \multicolumn{6}{|c|}{ CALÇADA } \\
\hline Julho & Agosto & sombra & sombra & sol & sol & $\begin{array}{c}\text { sombra } \\
\text { (b) * }\end{array}$ & $\begin{array}{c}\text { sombra } \\
(b)^{*}\end{array}$ & $\begin{array}{c}\text { sombra } \\
\text { (c) * }\end{array}$ & $\begin{array}{l}\text { sombra } \\
\text { (c) }{ }^{*}\end{array}$ & $\begin{array}{l}\text { sol } \\
\text { (d) * }\end{array}$ & $\begin{array}{l}\text { sol } \\
\text { (d) * }\end{array}$ \\
\hline \multirow{3}{*}{ Sibipiruna } & Média & 28,5 & 37,3 & 44,9 & 53,5 & 34,1 & 32,1 & 31,8 & 35,1 & 41,4 & 46,1 \\
\hline & DesvP & 0,63 & 5,49 & 1,51 & 7,42 & 10,1 & 3,49 & 4,34 & 5,65 & 7,36 & 0,86 \\
\hline & $\mathrm{CV}$ & $2 \%$ & $15 \%$ & $3 \%$ & $14 \%$ & $29 \%$ & $11 \%$ & $14 \%$ & $16 \%$ & $17 \%$ & $2 \%$ \\
\hline
\end{tabular}




\begin{tabular}{|c|c|c|c|c|c|c|c|c|c|c|c|}
\hline \multicolumn{2}{|c|}{$\begin{array}{c}\text { GRANDE } \\
\text { PORTE } \\
\text { Temperaturas }\end{array}$} & \multicolumn{4}{|c|}{ ASFALTO } & \multicolumn{6}{|c|}{ CALÇADA } \\
\hline \multirow{3}{*}{ Oiti } & Média & 28,3 & 31,9 & 48,5 & 53,8 & 29,8 & 28,6 & 27 & 28,1 & 42,7 & 46,7 \\
\hline & DesvP & 4,27 & 3,32 & 5,17 & 0,83 & 2,52 & 1,38 & 1,59 & 0,72 & 8,8 & 3,69 \\
\hline & $C V$ & $15 \%$ & $10 \%$ & $10 \%$ & $2 \%$ & $8 \%$ & $5 \%$ & $5 \%$ & $3 \%$ & $20 \%$ & $8 \%$ \\
\hline \multirow{3}{*}{ Ipê-roxo } & Média & 35 & 44 & 44,1 & 51,7 & 37,5 & 44,6 & 39,7 & 44,5 & 42,9 & 48,7 \\
\hline & DesvP & 3 & - & 3,72 & 2,19 & 7,1 & 4,8 & 7,12 & 5,65 & 5,56 & 1,62 \\
\hline & $C V$ & $8 \%$ & - & $8 \%$ & $4 \%$ & $18 \%$ & $11 \%$ & $17 \%$ & $13 \%$ & $12 \%$ & $3 \%$ \\
\hline \multirow{3}{*}{ Aldrago } & Média & 30,6 & 35,8 & 42,8 & 50,4 & 29,5 & 34,7 & 27,8 & 31,4 & 34,3 & 50,6 \\
\hline & DesvP & - & 2,87 & 2,83 & 3,96 & 0,85 & 4,3 & 1,94 & 2,55 & 1,36 & 3,2 \\
\hline & $\mathrm{CV}$ & - & $8 \%$ & $6 \%$ & $8 \%$ & $2 \%$ & $12 \%$ & $6 \%$ & $8 \%$ & $3 \%$ & $6 \%$ \\
\hline
\end{tabular}

*As letras se referem à localização da medição: (b) a 1 metro do tronco; (c) a 3 metros do tronco; (d) a 1 metro fora da sombra da copa/a pleno sol.

Fonte: Jussara Basso - 2012.

Verificou-se amenização generalizada de temperaturas superficiais (superfícies ao sol e à sombra) sob a copa das diferentes espécies. Os resultados indicaram que os dados de temperatura são homogêneos, exceto no caso da Quaresmeira, em que os coeficientes de variação se situaram acima de $20 \%$.

As árvores de grande e médio porte apresentaram as maiores reduções de temperatura superficial sob sua sombra, a não ser o lpê-roxo, cujos exemplares no período estavam, em vários casos, sem folhas e criavam algum sombreamento só com suas galhadas.

As maiores diferenças de temperatura superficiais levantadas sobre o asfalto foram sob as copas dos Oitis, em torno de $21^{\circ} \mathrm{C}$, e nas temperaturas superficiais das calçadas cimentadas à sombra da mesma espécie, em torno de $17^{\circ} \mathrm{C}$ de diferença entre a área sombreada pelos Oitis e áreas próximas a pleno sol (a 1 metro da sombra). As menores diferenças de temperatura superficial levantadas sobre o asfalto foram sob a espécie Escova-de-garrafa - perto de $9{ }^{\circ} \mathrm{C}$-, enquanto nas calçadas, a menor faixa de amenização da radiação solar foi constatada sob os Ipês desfolhados, $5,44^{\circ} \mathrm{C}$. Considerando a existência de folhagem, as pequenas Resedás proporcionam amenização de $6,7^{\circ} \mathrm{C}$, a segunda menor amenização sobre o passeio público, amenizações sensivelmente menores que os $17^{\circ} \mathrm{C}$ trazidos pelos Oitis.

Na figura 5, está representada a amenização das temperaturas das superfícies, nos passeios e no asfalto, sob copas das diversas espécies arbóreas avaliadas, em ordem decrescente. 


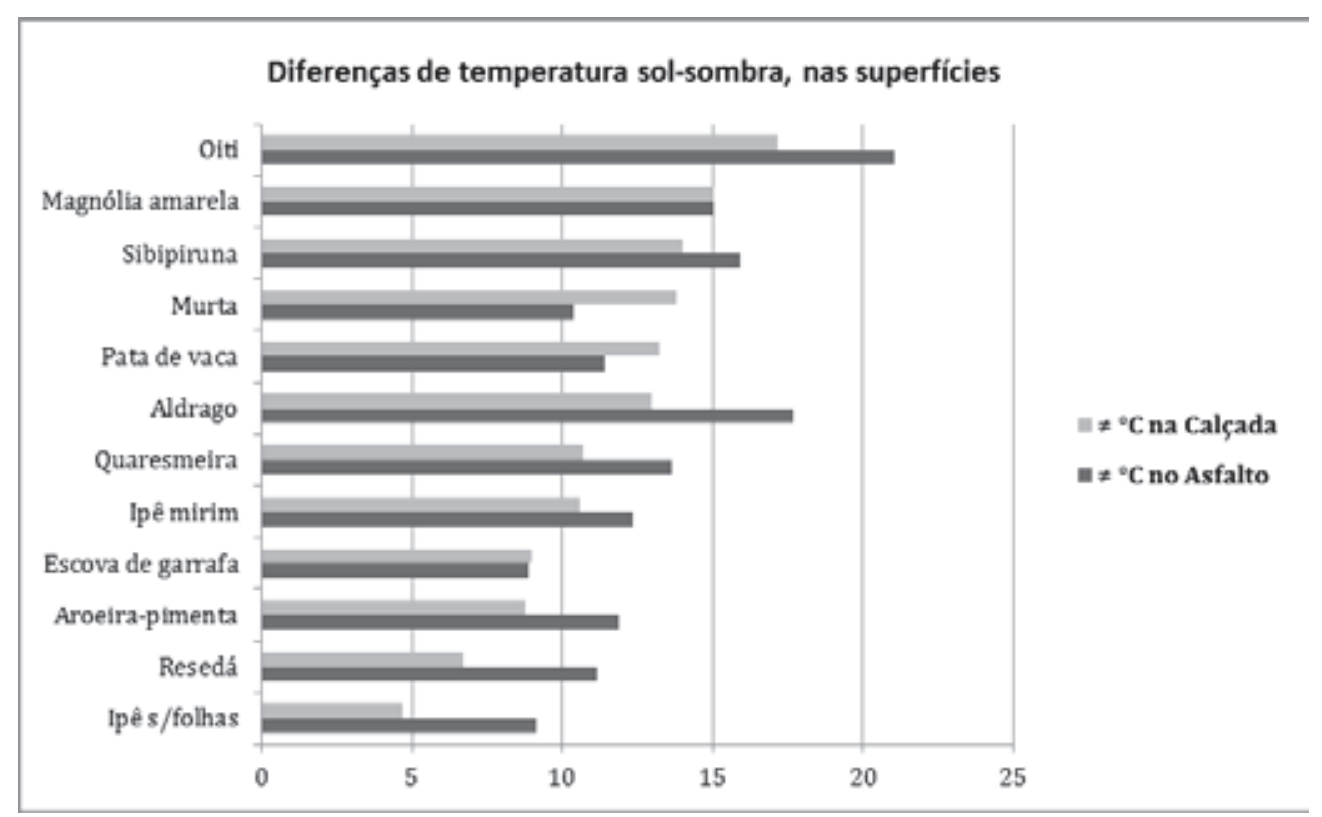

Figura 5 Gráfico da amenização das temperaturas superficiais sob diferentes espécies arbóreas. Fonte: Jussara Basso - 2012

Os Oitis avaliados possuíam copas médias de 17,5 metros e sombra projetada de $240 \mathrm{~m}^{2}$. Com isso podemos fazer algumas considerações sobre a amenização das temperaturas superficiais em um recinto urbano utópico: imaginemos um segmento de rua de $100 \mathrm{~m} \times 20 \mathrm{~m}$, sendo 12 metros asfaltados para uso dos veículos e 8 metros de passeio público, 4 metros a cada lado da via (figuras 6 e 7) - configuração comum a muitas ruas da área central de Campo Grande.

Dois pequenos estudos de composições com arborização urbana, utilizando a capacidade máxima de árvores de grande e de pequeno porte que o espaço permite, exemplificam a possibilidade de uma estratégia de projeto que busque coordenar embelezamento e amenização da temperatura no recinto urbano. Aqui, abstraíram-se outras variáveis para estudar o efeito na amenização térmica. Inúmeras combinações são possíveis dependendo do foco pretendido, inclusive alternando espécies de grande porte com pequeno ou médio porte ou espécies floríferas com espécies de sombra mais densa, de forma a conseguir resultados agradáveis tanto paisagisticamente quanto ambientalmente.

Na figura 6, temos a simulação de uso de nove Oitis do porte dos avaliados neste trabalho (194,36 $\mathrm{m}^{2}$ de sombreamento da área pública cada um), sombreando total de $1.749 \mathrm{~m}^{2}$ dos $2.000 \mathrm{~m}^{2}$ daquele recinto urbano, ou seja, $87 \%$ de sua área fica sombreada com temperaturas superficiais de $17^{\circ} \mathrm{C}$ a $21^{\circ} \mathrm{C}$, menores que as das superfícies não sombreadas do entorno, ou seja, um ambiente fartamente sombreado, com expressiva diminuição das temperaturas superficiais.

Na figura 7, a distribuição de árvores de pequeno porte, como Resedás, com espaçamento de 5 metros, o que permite sombreamento de $551 \mathrm{~m}^{2}$ - ou seja, 27,5\% da 
área daquele recinto urbano -, apresentaria temperaturas das superfícies amainadas, em média $6,7^{\circ} \mathrm{C}$. Portanto, apesar do menor espaçamento de plantio, a maior parte do recinto urbano permanece recebendo a radiação solar total, com temperaturas superficiais diminuídas - menos fortemente à sombra dos Resedás do que dos Oitis.

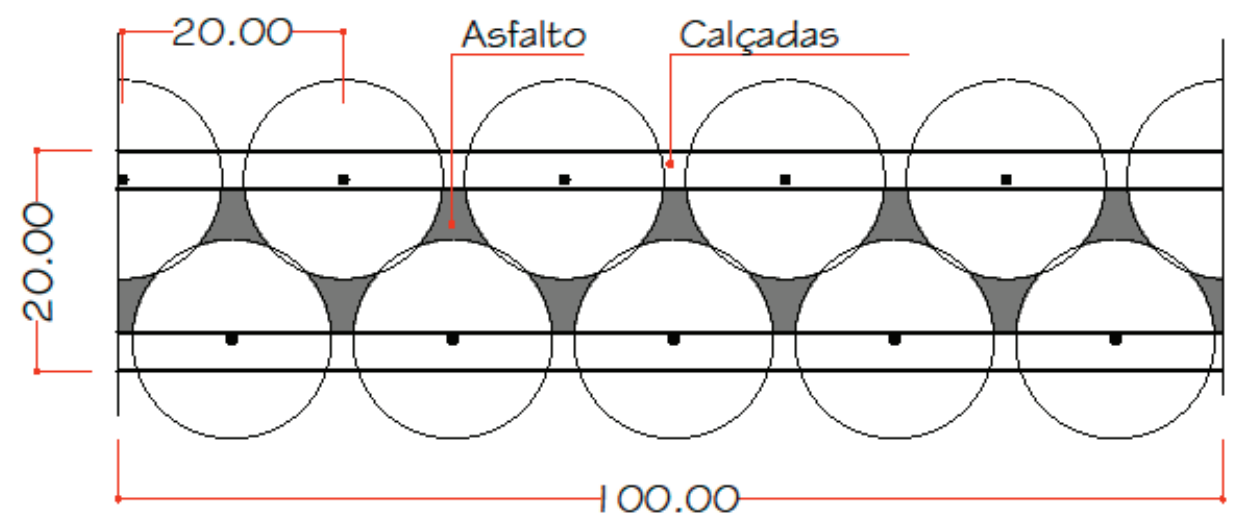

Figura 6 Simulação com espécies de grande porte. Fonte: Jussara Basso - 2012.

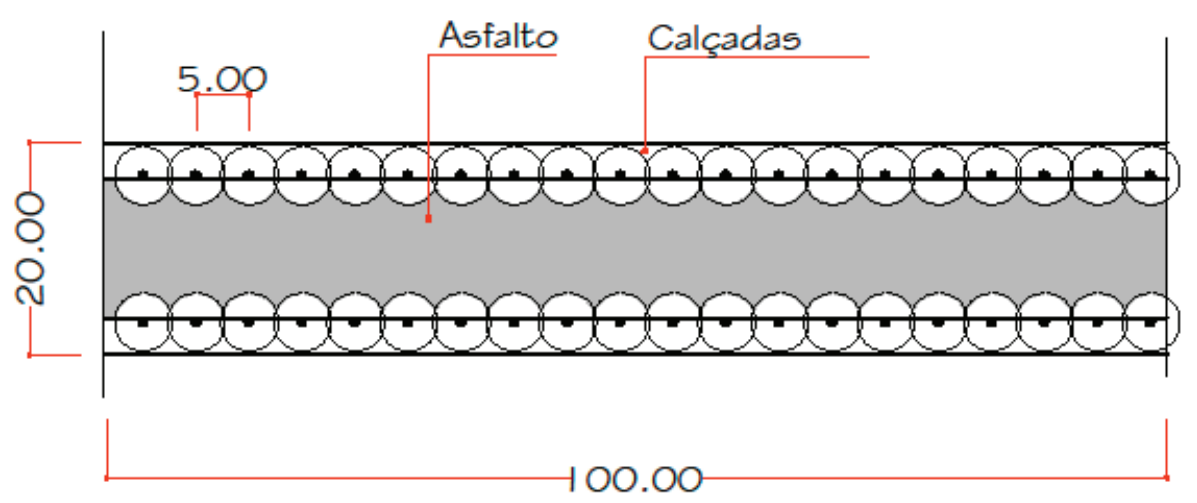

Figura 7 Simulação com espécies de pequeno porte. Fonte: Jussara Basso - 2012.

Nos dois casos, a diminuição da radiação solar nas superfícies contribui para a amenização da temperatura do ar, trazendo maior conforto térmico nos horários de grande insolação, porém, no estudo com árvores de grande porte, o impacto positivo será fortemente maior, tanto pela área sombreada em si quanto pela maior diminuição da temperatura superficial.

A partir desses estudos básicos, outros desenhos de composições mais dinâmicas podem ser explorados para diferentes casos, e com variações de sombreamento das superfícies de piso, como exemplificado nas figuras 8 e 9 . 


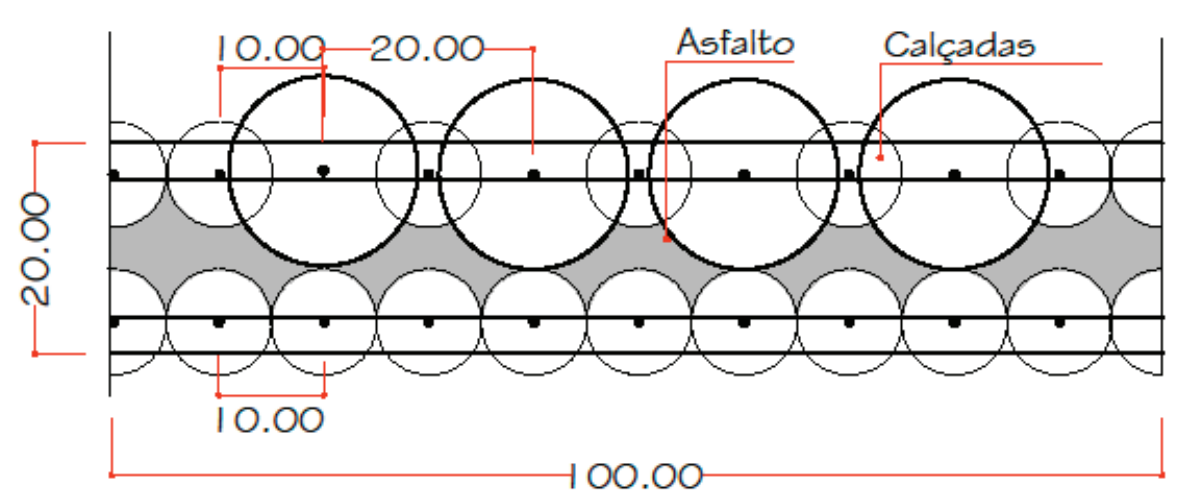

Figura 8 Composição com espécies de grande e médio porte. Fonte: Jussara Basso - 2012.

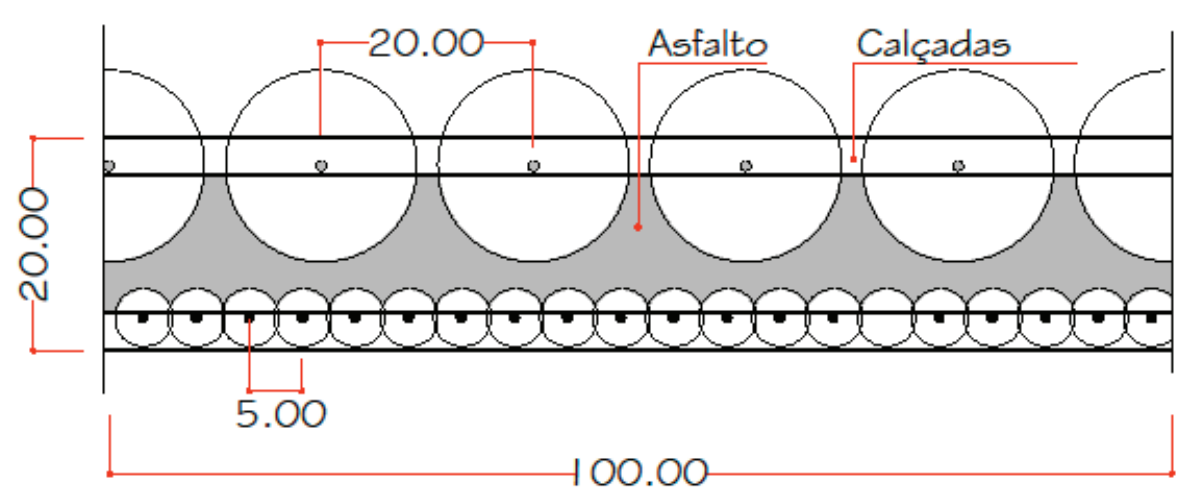

Figura 9 Composição com espécies de grande e pequeno porte. Fonte: Jussara Basso - 2012

\section{CONCLUSÕES}

Considerando o estágio deste estudo, e até onde foi conduzido, pode-se concluir que é verdadeira a afirmação de que existe influência diferenciada na temperatura das superfícies dos espaços das ruas e calçadas sob diferentes espécies arbóreas. Dentre as espécies avaliadas, a mais efetiva para a redução das temperaturas superficiais decorrentes da radiação solar incidente foi o Oiti (Licania tormentosa). A espécie com menor eficiência, o lpê (Tabebuia heptaphylla), que se encontrava sem folhas nos meses das medições. Dentre as espécies que mantinham suas folhas na época de mensuração da temperatura, menos eficiente para a redução das temperaturas superficiais foi o Resedá (Lagerstroemia indica). 
Reforça-se, então, que em cidades de clima quente e seco a atenuação da radiação solar é um parâmetro influente, que deve ser levado em conta na escolha das espécies ao se planejar e projetar espaços de uso público, para que se tornem ambientalmente mais confortáveis e qualificados. Nesse sentido, há indicação da importância da escolha de espécies de porte elevado e com boa densidade de sombreamento.

\section{REFERÊNCIAS BIBLIOGRÁFICAS}

AIT-AMEUR, Karima. Validation of a thermal comfort index for public outspaces. In: ENCONTRO NACIONAL DE CONFORTO NO AMBIENTE CONSTRUÍDO (ENCAC), 5 e ENCONTRO LATINO-AMERICANO DE CONFORTO NO AMBIENTE CONSTRUÍDO (ELACAC), 2 Fortaleza, Ceará. Anais do ENCAC, 1999.

AMORIM, Cláudia Naves David; BRAGA, Darja Kos. Métodos e técnicas para conforto ambiental e reabilitação do espaço construído. In: Reabilita: reabilitação ambiental sustentável arquitetônica e urbanística. Texto didático. Brasília: FAUUnB, 2009, p. 618-683.

BARBIRATO, Gianna Melo; TORRES, Simone Carnaúba; SOUZA, Lea Cristina Lucas de. Clima urbano e eficiência energética nas edificações. Programa Nacional de Eficiência Energética em Edificações - PROCEL EDIFICA. Rio de Janeiro, ago. 2011. Disponível em: <www.procelinfo.com.br>. Acesso em: 12 mar. 2012.

BUENO, Carolina L. Bartolomei; LABAKI, Lucila C.; SANTOS, Rozely F. dos. Estudo da atenuação da radiação solar incidente por diferentes espécies arbóreas. In: ENCONTRO NACIONAL, 5 / ENCONTRO LATINOAMERICANO DE CONFORTO NO AMBIENTE CONSTRUÍDO, 2, 1999, Fortaleza. Anais do V Associação Nacional de Tecnologia do Ambiente Construído (ENCAC). Fortaleza: ANTAC, 1999.

; ___ VIANNA, Priscila Z. Comportamento de diferentes espécies arbóreas quanto à atenuação da radiação solar. In: ENCONTRO NACIONAL DE CONFORTO NO AMBIENTE CONSTRUÍDO, 6 / ENCONTRO LATINO-AMERICANO DE CONFORTO NO AMBIENTE CONSTRUÍDO, 3, 2001. São Pedro, SP. Anais do VI ENCAC, 2001.

ROMERO, Marta Adriana Bustos. A arquitetura bioclimática do espaço público. Brasília: Editora Universidade de Brasília, 2001. 225 p.

; Arquitetura do lugar: uma visão bioclimática da sustentabilidade em Brasília. São Paulo: Nova Técnica

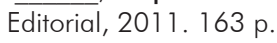

CAMPOS, Ana Cecília de Arruda et al. Análise do sistema de espaços livres da cidade brasileira - uma metodologia em construção: estudo de caso para o município de São Paulo. Paisagem e Ambiente: ensaios, n. 26, São Paulo: FAUUSP, 2009, p. 197-210.

CORMIER, Nathaniel S.; PELLEGRINO, Paulo Renato Mesquita. Infraestrutura verde: uma estratégia paisagística para a água urbana. Paisagem e Ambiente: ensaios. FAUUSP, São Paulo, n. 25, 2008, p. 127-142.

CORBELLA, Oscar; YANNAS, Simos. Em busca de uma arquitetura sustentável para os trópicos. Rio de Janeiro: Revan, 2003. 287 p.

EBNER, Iris de Almeida Rezende. A cidade e seus vazios: investigação e proposta para os vazios de Campo Grande. Campo Grande: UFMS, 1999. 212 p.

MASCARÓ, Lucia; MASCARÓ, Juan L. Vegetação urbana. Porto Alegre: Mais Quatro Editora, 2002. 204 p.

PEREIRA, Iraci Miranda; ASSIS, Eleonora Sad de. Avaliação de modelos de índices adaptativos para uso no projeto arquitetônico bioclimático. Ambiente Construído, Porto Alegre: Associação Nacional de Tecnologia do Ambiente Construído (ANTAC); UFRGS, 2010. Disponível em:

<seer.ufrgs.br/índex.php/ambientecosntruido/article/view/6319/7490>. Acesso em: 12 mar. 2012.

PREFEITURA DE CAMPO GRANDE. Plano Diretor de Arborização Urbana de Campo Grande (PDAU), 2010.

Disponível em <www.capital.ms.gov.br/egov/downloadFile.ph>. Acesso em: 20 jan. 2012. 
Jussara Maria Basso e Rodrigo Studart Corrêa 